\title{
CLINICAL AND THERAPEUTIC STUDIES ON DERMATOPHILOSIS OF SHEEP AND GOATS IN QUASSIM, KINGDOM OF SAUDI ARABIA
}

\author{
SALAMA A. OSMAN ${ }^{1,2}$ \\ ${ }^{1}$ Department of Veterinary Medicine, College of Agriculture and Veterinary Medicine, Qassim University, 51452 Buraydah, \\ Qassim, Saudi Arabia. \\ ${ }^{2}$ Animal Medicine Department, Faculty of Veterinary Medicine, Kafrelsheikh University, 33516, Kafrelsheikh-Egypt.
}

\section{ABSTRACT}

Received at: $25 / 8 / 2015$

Accepted: 6/9/2015
This study was conducted in Qassim region, central of Saudi Arabia to study the clinical signs associated with dermatophilosis in sheep and goats with therapeutic trials using two treatment regimes. Diagnosis of dermatophilosis was based on the appearance of the characteristic skin lesions on the affected animals and demonstrating the causal organism from the lesions beneath the scabs. Clinically, the examined diseased sheep and goats showed lesions in the form of exudative dermatitis and formation of thick greasy scabs. These lesions were mainly observed on the back of the infected animals. All cases were detected during November, December and January (2013 and 2014). Treatment of the infected animals using long acting oxytetracycline, 3 doses 3 days apart gave the same results as penicillin plus streptomycin administered for five consecutive days. From the technical point of view, it is recommend that long acting oxytetracycline, 3 doses 3 days apart are less demanding than penicillin plus streptomycin for five consecutive days.

Key words: Sheep; Goats, Dermatophilosis, Signs, Treatment.

\section{INTRODUCTION}

Dermatophilosis is an acute, subacute or chronic skin disease affecting primarily in cattle, small ruminants, equidae, humans and certain nondomesticated species. It is caused by a gram positive bacteria of the order of the Actinomycetales named Dermatophilus congolensis (D. congolensis). (Dickson et al., 2010). The disease is non-pruritic, and is characterized by exudative, proliferative or hyperkeratotic dermatitis, accompanied by the production of crusts and foliculitis (Zaria, 1993). Several factors are involved in the pathogenesis of dermatophilosis; among them are mechanical injury to the skin, rainfall, tick infestation, concurrent diseases and/or stresses that compromise the host's immune system (Yeruham et al., 1995; Amabrose, 1996).

Diagnosis of dermatophilosis is mainly based on the appearance of the characteristic skin lesions and confirmed by the demonstration of the causal organism from the lesions beneath the scabs (Gebreyohannes and Gebresselassie, 2013). From economic point of view, Poor quality hides (Woldemeskel, 2000 and Norris et al., 2010), low meat production and decrease in milk production
(Dalis et al., 2007) with losses of body condition (Wilkinson, 1979) are the major economic losses associated with dermatophilosis. Moreover, the disease plays a role in public health and can be transmitted to human (Harman et al., 2001; Burd et al., 2007; Dalis et al., 2010 and Dickson et al., 2010). The aims of the present study were to study the clinical signs of Dermatophilosis in sheep and goats located in Quassim, Saudi Arabia.and therapeutic trials of infected cases.

\section{MATERIALS and METHODS}

\section{Animals and samples collection:}

In Veterinary Teaching Hospital, Qassim University, Central of Saudi Arabia, 20 cases of D. congolensis -infected animals (10 sheep and 10 goats) were studied. They were come from different localities and are reared in flocks. Heavy scabs were collected in clean sterile petri-dishes for microscopic detection and isolation of D. congolensis. Parasitological and mycological examinations were also carried out for the collected samples.

\section{Clinical examination:}

All animals under study were subjected to careful clinical examination. 
Skin scraping for parasitological examination:

Deep skin scrapings were collected from the edges of suspected active lesions of the affected skin was carried as described by Fowler (2010).

\section{Mycological examination:}

The scraped materials were divided into two parts; the first was subjected to direct microscopic examination for detection of dermatophytes spp. and the second for culture on Sabouraud Dextrose Agar Media (SDA) supplemented by chloramphenicol and cycloheximide. The media kept at $27^{\circ} \mathrm{C}$ for $3-4$ weeks (Quinn et al., 1994).

\section{Bacteriological Examination for detection of Dermatophilus congolensis:}

1 - Impression smears: Multiple impression smears were taken, prepared and stained by Giemsa stains and microscopically examined (Quinn et al., 1994; OIE 2004).

2- Culturing of $\boldsymbol{D}$. congolensis: It was collected samples were culturally on sheep blood agar using the procedures described by Haalstra (1965) and OIE (2004).

\section{Therapeutic trials:}

Diseased animals were divided into two main groups each of 5 sheep and 5 goats. The first group was treated using long acting oxytetracycline (Terramycin /LA®, Pfizer) 3 doses 3 days apart as deep intramuscular injection $(1 \mathrm{ml} / 10 \mathrm{Kg} \mathrm{B.W})$, each 1 $\mathrm{ml}$. contains $200 \mathrm{mg}$ oxytetracycline. Topical application of Povidone iodine 5\% W/V (Iodosav spray, Saudi Pharmaceutical Industries) was sprayed daily for 10 days. The second group was treated using penicillin-streptomycin (Pen \& Strep/ NorBrook Co.) administered by deep intramuscular once daily for 5 consecutive days at doses of $8 \mathrm{mg}$ procaine penicillin and $10 \mathrm{mg}$ dihydrostreptomycin sulphate per $\mathrm{kg}$ bodyweight achieved by administering $1 \mathrm{ml}$ Pen \& Strep per $25 \mathrm{~kg}$ bodyweight. Topical treatment was also sprayed as described. Heavy crusts were aseptically removed before treatment in both groups. Treated animals were moved to dry place. Ticks control was done in all groups and their environment using $200 \mu \mathrm{g} / \mathrm{Kg} \mathrm{BW}$ Ivermectin (Ivomec, Merial) two subcutaneous injections, 15 days apart for the animals and 1/1000 Diazinon (Nucedol Ultra 60 EC,
Bioagripharm, Germany) two times, one week apart for the environment.

\section{RESULTS}

The results of parasitological and mycological examination of the examined skin scraping revealed no mites or derrmatophytes. Also culturing on SDA media did not yield any fungal growth.

Bacteriologically, the characteristic colonies of $D$. congolensis was monitored post 24-48 hrs incubation as small, grey-yellow colour adhered to the surface of the agar. Three - days incubation, the colonies tend to become more wrinkled and the yellow pigmentation more intense. A zone of beta-hemolysis was observed around each colony. D. congolensis (Figure 1) had a characteristic microscopic appearance where it seen as septate, branching filamentous hyphae become longitudinally, as well as transversely, divided to form spherical cocci in multiple rows.

The observed clinical signs of diseased sheep and goats were illustrated in Figure $2 \mathrm{a}$ and $2 \mathrm{~b}$. The lesions may be localized or generalized according to the stage of the disease. Localized lesions mainly seen along the back of the animal from the withers to the rump and extend to the midlateral aspect. The lesions were in the form of exudative dermatitis and scabs formation. Wool or hairs were matted to each other to form paint brush appearance. Removal of these matted wool in the early stage of the disease revealed severe pain leaving bleed area beneath it but later and in old lesion, the wool were easily removed without pain. In generalized shin affection, the body condition of the animal was affected. All infected cases were occurred during November, December and January.

Concerning the efficacy of the therapeutic trials (Table 1), treatment using long acting oxytetracycline in addition to topical application of povidone iodine $5 \%$ gave the same cure rate as treatment using penicillin- streptomycin in addition to the same topical application. Clinical and bacteriological cures were achieved at the $4^{\text {th }}$ week post treatment representing a $100 \%$ cure rate in both groups.

Table 1: Results of the treatment trials in the examined diseased animals

\begin{tabular}{|c|c|c|c|c|c|c|c|}
\hline \multirow{2}{*}{$\begin{array}{l}\text { Treated } \\
\text { group }\end{array}$} & \multirow{2}{*}{$\begin{array}{c}\text { No. } \\
\text { treated } \\
\text { animals }\end{array}$} & \multicolumn{4}{|c|}{ No. of cured animals at week (w) } & \multirow{2}{*}{$\begin{array}{l}\text { Total No. of the } \\
\text { cured cases }\end{array}$} & \multirow[t]{2}{*}{ Cure $(\%)$} \\
\hline & & $1^{\text {st }}(w)$ & $2^{\text {nd }}(w)$ & $3^{\text {rd }}(w)$ & $4^{\text {th }}(w)$ & & \\
\hline First & 10 & 1 & 4 & 2 & 3 & 10 & 100 \\
\hline Second & 10 & 0 & 4 & 4 & 2 & 10 & 100 \\
\hline
\end{tabular}




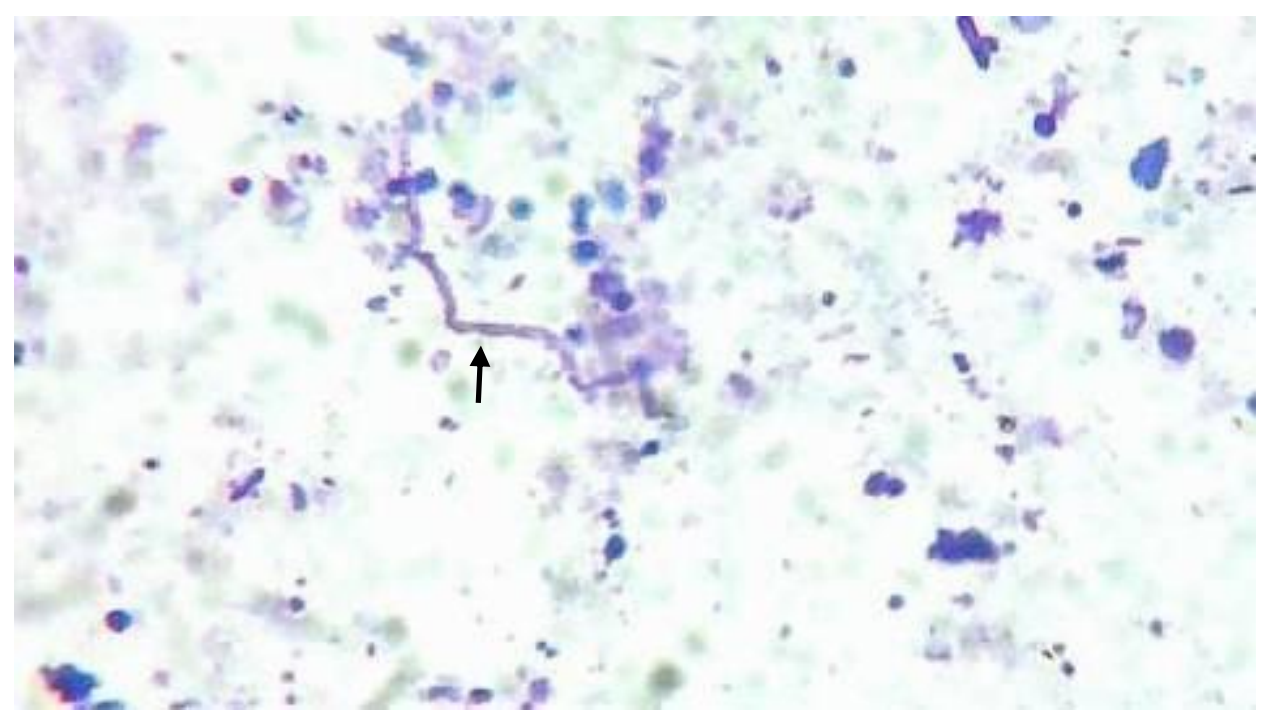

Fig. 1: Giemsa stained direct smear showing branched septated hyphae (The arrow) and zoospores of Dermatophilus congolensis (X 1000).
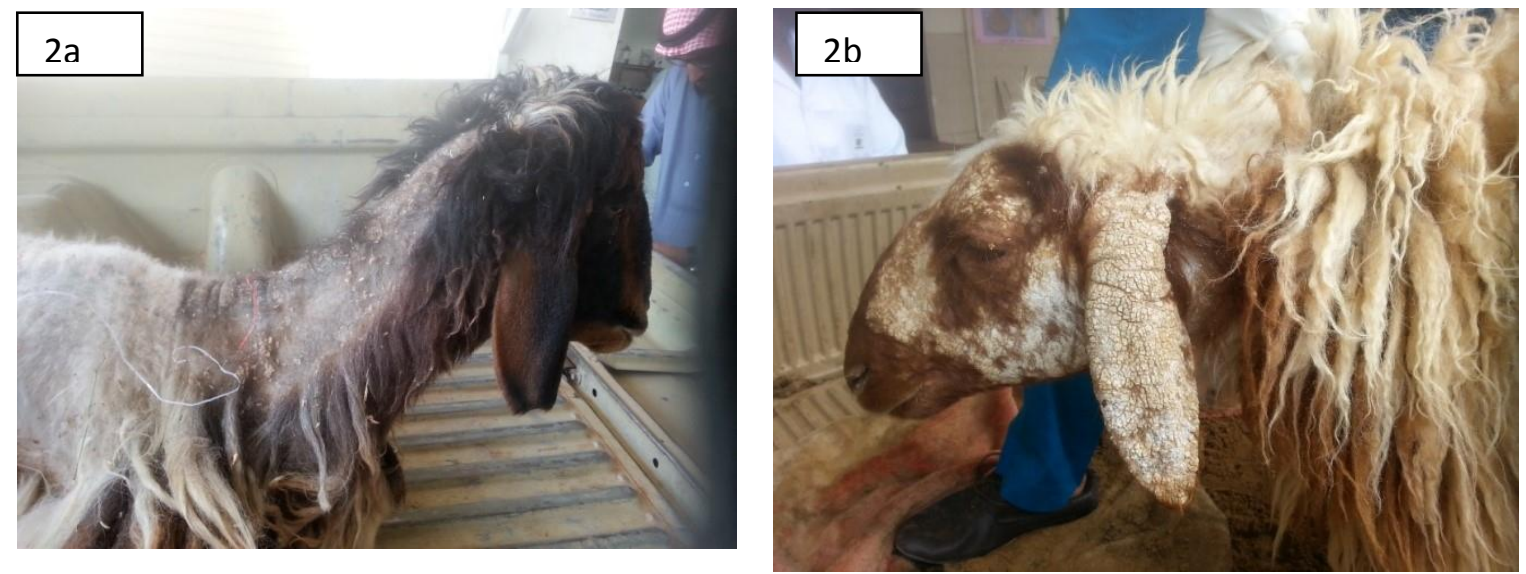

Fig. 2a (Goat) and 2b (sheep): Cutaneous lesions: remarkable exudative dermatitis with crusty wrinkled fissured skin lesion on head including ears (sheep) and dorsal view of goat particularly neck

\section{DISCUSSION}

In this study neither mites nor derrmatophytes spp. were detected in the examined skin scraping of diseased animals. Also culturing on SDA media did not yield any fungal growth. Whereas, D. congolensis was detected in direct smears and identified via culturing on sheep blood agar with $10 \%$ CO2 atmosphere. Similar colonial and microscopical characters were previously observed by Masters et al. (1997), Rapuntean and Rapuntean (2005), and Awad et al. (2008).

The observed clinical signs of diseased animals were exudative dermatitis and formation of thick greasy scabs. Similar lesions were observed previously by Gitao (1993), and Awad et al. (2008). In the epidermis, the bacterial hyphae that developed from the spores attack the hair sheath and produce an exudative inflammatory reaction, resulting in a bulging of the slow growing epidermis away from the corium, thereby allowing growth of a new layer of epidermal cells (Seifert, 1992). Drying of the serous exudate forms a crust that is a distinguishing characteristic of this disease.

From epidemiological point of view, the development of dermatophilosis is facilitated by factors such as wetting and mechanical trauma of the skin by ectoparasites that reduce the defence barriers of skin (Zaria, 1993; Ambrose et al., 1999). In the present study, all cases of the disease were observed during November, December and January months. This finding may be attributed to the heavy rains in Qassim region during this period. Similar results were previously reported by Zaria (1993) who mentioned that in the rainy season due to devitalizing effects of saturation on skin barriers, humidity has a remarkable influence in the maturation and motility of the infective zoospores and weather generally exerts complex biological effects on the prevalence and activity of the arthropod vectors. Also, the hyphae produce motile spores (zoospores) that are predominantly released during the rainy season and 
are transmitted either by direct contact or by vectors (ticks, flies).

Therapeutically, treatment of the infected animals using long acting oxytetracycline was not differed significantly from treatment using penicillinstreptomycin. Clinical and bacteriological cures were achieved at the 4th week post treatment representing a $100 \%$ cure rate in both groups. Previously, Ilemobade (1984), Aning and Koney (1996), Awad et al. (2008), Nath et al. (2010) and Gebreyohannes and Gebresselassie (2013) reported the efficacy of long acting oxytetracyclines in the treatment of animal dermatophilosis. Also Gbodi and Ndife (1982), Rosyehuk (1989), Yeruham et al. (1995), Reed et al. (2004) and Aitken (2007) proved the efficacy of penicillin in the treatment of animal dermatophilosis.

Gebreyohannes and Gebresselassie (2013) mentioned that the topical treatment had limited efficacy in the treatment where these application did not penetrate the scab to the active lesion and were more appropriate for control. Also Dickson et al. (2010) reported that the application of topical antiseptics was of questionable value because the drug had no action on the hyphae found inside woolly follicles; nevertheless they do contribute to reduce the spread of the infection through the destruction of the organisms present in the crusts.

It is concluded that, dermatophilosis in sheep and goats showed lesions in the form of exudative dermatitis and formation of thick greasy scabs. Treatment using long acting oxytetracycline, 3 doses 3 days apart or penicillin-streptomycin for 5 days and keep treated animals in dry place gave $100 \%$ cure rate after 4 weeks. There were no differences between two drugs. From the technical point of view, it is recommend that long acting oxytetracycline, 3 doses 3 days apart are less demanding than penicillin plus streptomycin for five consecutive days.

\section{REFERENCES}

Aitken, I.D. (2007): Diseases of Sheep and Goats. The $4^{\text {th }}$ ed. United Kingdom: Black Well Science; P. 315-316.

Amabrose, N.C. (1996): The pathogenesis of dermatophilosis. Trop Anim Health Prod. 28: 29-37.

Ambrose, N.; Lloyd, D. and Maillard, J.C. (1999): Immune responses to Dermatophilus congolensis infections. Parasitol Today 15: 295300.

Aning, K.G. and Koney, E.M.B. (1996): Chemotherapy of Dermatophilosis - A preliminary study. Trop. Anim. Health. Prod., 28: 39S-43S.

Awad, W.S.; Abdou, N.E.M.I. and El-Sayed, A.A. (2008): Diagnosis and treatment of bovine, ovine and equine dermatophilosis. J. Appl. Sci. Res., 4: 367-374.

Burd, E.M.; Juzych, L.A.; Rudrik, J.T. and Habib, F. (2007): Pustular dermatitis caused by Dermatophilus congolensis. J. Clin. Microbiol., 45: 1655-1658.

Dalis, J.S.; Kazeem, H.M.; Makinde, A.A. and Fatihu, M.Y. (2007): Agalactia due to severe generalized dermatophilosis in a white Fulan cow in Zaria, Nigeria. VJVS, 1: 56-58.

Dalis, J.S.; Kazzem, H.M.; Makinde, A.A. and Fatihu, M.Y. (2010): Bacteria associated with Bovine Dermatophilosis in Zaria, Nigeria. Afr. J. Microbiol., 4: 1475-1476.

Dickson, C.; Rosa, M. and Elías-Costa, D. (2010): Human and animal dermatophilosis. An unusual case report and review of the literature. Dermatol. Argent., 16: 349-353

Fowler, M.E. (2010): Medicine and Surgery of Camelids $3^{\text {rd }}$ Edition. Blackwell Publishing.

Gbodi, T.A. and Ndife, L. (1982): Some observations on chemotherapy of bovine dermatophilosis. Br. Vet. J., 138(4): 288-94.

Gebreyohannes, M. and Gebresselassie, M. (2013): An Overview on Dermatophilosis of Animals: a Review. J. Anim. Sci. Adv., 3: 337-344

Gitao, C.G. (1993): The epidemiology and control of camel dermatophilosis. Rev. Elev. Med. Vet. Pay., 46: 309-311.

Haalstra, R. (1965): Isolation of Dermatophilus congolensis from skin lesions in the diagnosis of streptothricosis. Vet. Rec., 77: 824-834.

Harman, M.S.; Sekin, S. and Akdeniz, S. (2001): Human dermatophilosis mimicking ringworm. Brit. J. Derm., 145: 170-1.

Ilemobade, A.A. (1984): Clinical experiences in the use of chemotherapy of bovine dermatophilosis in Nigeria. Prev. Vet. Med., 2: 83-92.

Masters, A.M.; Ellis, M.T. and Grein, S.B. (1997): Dermatophilus congolensis'. Strain difference in expression of phospholiphase activities, Vet. Microbiol, 51: 199-213.

Nath, B.D.; Ahasan, S.; Rahman, S. and Huque, A.K.M.R. (2010): Prevalence and Therapeutic Management of Bovine Dermatophilosis. Bangladesh Res. Pub. J., 4: 198-207.

Norris, B.J.; Colditz, I.G. and Dixon, T.J. (2008): Fleece rot and dermatophilosis in sheep. Vet. Microbiol., 128: 217-230.

OIE (Office International De Epizootics) (2004): Manual of diagnostic tests and vaccine for terrestrial animals: Dermatophilosis. $5^{\text {th }}$ Edition. Retrieved from: http:// www.oie.int/Dermatophilosis.

Quinn, PJ.; Carter, M.E.; Markey, B. and Carter, G.R. (1994): Clinical Veterinary 
Microbiology. Mosby year book Europe limited.

Rapuntean, G. and Rapuntean, S. (2005):

Bacteriologie Veterinara Speciala $\mathrm{I}^{\text {st }}$ ed. Editura Academic Press, Cluj-Napoca, Romania.

Reed, M.S.; Bayly M.W. and Sellon, C.D. (2004):

Equine Internal Medicine. $2^{\text {nd }}$ ed. Philadelphia: Saunders. Pp. 683-684.

Rosyehuk, R.A. (1989): Llama dermatology. Vet. Clin. North. Am. Food. Anim. Pract. Mar; 5(1): 203-215.

Seifert, H.S.H. (1992): Tropentierhygiene. Gustav

Fischer Verlag Jena, Stuttgart.
Wilkinson, F.C. (1979): Dermatophilosis of sheep Association with dipping and effects on production. Aust. Vet. J., 55: 74-76.

Woldemeskel, M. (2000): Dermatophilosis a threat to livestock production in Ethiopia. Dtsch Tierarztlwschr 107: 144-146

Yeruham I.; Elad D. and Nyska, A. (1995): Skin diseases in a Merino sheep herd related to an excessively rainy winter in a Mediterranean climatic zone. J. Vet. Med B, 42: 25-40.

Zaria, LT. (1993): Review: Dermatophilus congolensis infection (Dermatophilosis) in animals and man! An update. Comp. Immunol. Microbiol. infect. Dis., 16: 179-222.

\section{دراسـات إكلينيكية وعلاجية عن داء المجتلدات فى الأغنام والماعز بالقصيم - المملكة العربية السعودية سلامة أحمد عثمان

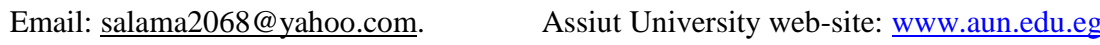

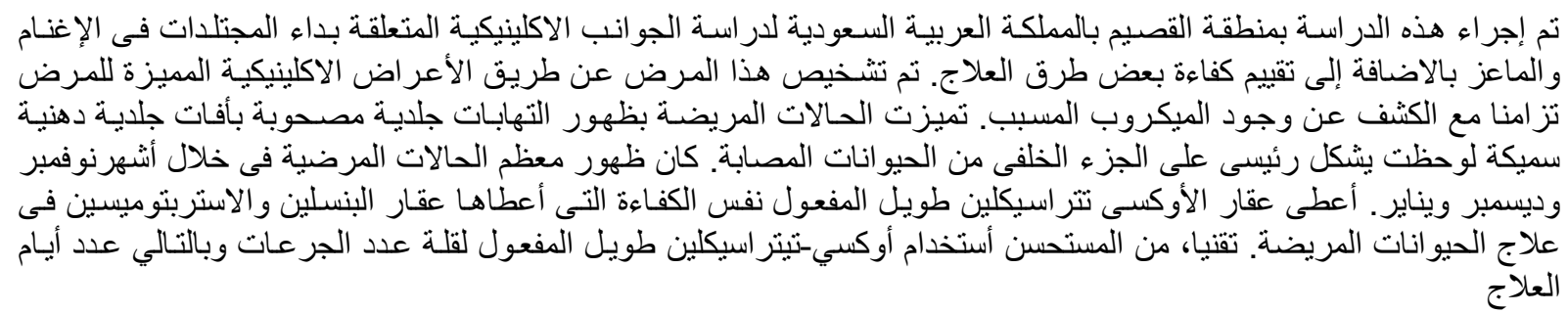

